\title{
Dez anos de CNJ: reflexões do envolvimento com a melhoria da eficiência do Judiciário brasileiro
}

\author{
Leonel Gois Lima Oliveira \\ Fundação Getúlio Vargas (FGV) \\ Escola Superior de Magistratura do Estado do Ceará (Esmec)
}

O objetivo deste ensaio é trazer reflexões sobre os dez anos de existência do Conselho Nacional de Justiça (CNJ) e a sua atuação na melhoria dos níveis de eficiência do Judiciário brasileiro. O ensaio discute e aponta lacunas ao propor a realização de estudos futuros sobre a gestão do Poder Judiciário. Os seguintes aspectos são abordados: Reforma do Judiciário e suas perspectivas; planejamento estratégico e metas anuais; mensuração de desempenho e eficiência. As reflexões propostas, no campo teórico e metodológico, podem ser incorporadas a modelos e práticas que buscam evidenciar um Judiciário mais célere e efetivo.

Palavras-chave: poder judiciário, reforma judiciária, planejamento estratégico, avaliação de desempenho, eficiência

\section{Diez años del CNJ: reflexiones sobre la participación en la mejora de la eficiencia del Poder Judicial brasileño}

El propósito de este ensayo es llevar a reflexiones sobre los diez años del Consejo Nacional de Justicia (CNJ) y su papel en la mejora de los niveles de eficiencia de la justicia brasileña. El ensayo discute y señala lagunas mediante la propuesta de llevar a cabo más estudios sobre el control del Poder Judicial. Los siguientes aspectos están cubiertos: reforma del sistema judicial y sus perspectivas; la planificación estratégica y las metas anuales; la medición de rendimiento y eficiencia. Las reflexiones propuestas, en el campo teórico y metodológico, se pueden incorporar en los modelos y prácticas que tratan de mostrar un Poder Judicial más rápido y eficaz.

Palabras clave: poder judicial, reforma judicial, planificación estratégica, evaluación del desempeño, eficiencia

[Artigo recebido em 3 de abril de 2016. Aprovado em 6 de abril de 2017.] 
Ten years of CNJ: reflections on involvement with improving the efficiency of the Brazilian Judiciary

The purpose of this essay is to bring reflections on the ten years of the National Council of Justice (CNJ) and its role in the improvement of the efficiency levels of Brazilian Judiciary. The essay discusses and points out gaps by proposing to carry out further studies on the management of the Judiciary Branch. The following aspects are covered: reform of the Judiciary and its prospects; strategic planning and annual goals; measurement of performance and efficiency. The reflections proposed in the theoretical and methodological field can be incorporated into models and practices that seek to show a more rapid and effective Judiciary.

Keywords: judiciary, judicial reform, strategic planning, performance evaluation, efficiency 


\section{Introdução}

O Judiciário brasileiro é percebido habitualmente pela lentidão na resolução dos conflitos, os elevados custos, a falta de transparência de suas atividades, ao que se soma a sensação de impunidade. Os problemas não são recentes e foram evidenciados por pesquisas de opinião e, principalmente, pela imprensa, sobressaindo-se a percepção de que o Judiciário brasileiro não funciona de forma satisfatória (Ordem dos Advogados do BrAsil, 2003; SAdeK, 2004, 2006). Porém, ao longo da década de 2000, inúmeras mudanças ocorreram, o que já permitiu visualizar melhorias no nível de satisfação do brasileiro em relação ao Judiciário. Mesmo assim, ainda há vários aspectos a serem aperfeiçoados, principalmente para transformar algumas opiniões enraizadas no senso comum do brasileiro sobre o Poder Judiciário (FALCÃO, 2009).

O objetivo deste ensaio é trazer reflexões sobre a atuação do Conselho Nacional de Justiça (CNJ), nos seus dez anos de existência, em relação à melhoria dos níveis de eficiência do Judiciário brasileiro. Desse modo, o ensaio discute e aponta lacunas que demandam a realização de estudos futuros sobre a gestão do Poder Judiciário brasileiro. Os seguintes aspectos são abordados: Reforma do Judiciário e suas perspectivas; planejamento estratégico e metas anuais; e mensuração de desempenho e eficiência.

A Emenda Constitucional (EC) no 45/2004, a chamada Reforma do Judiciário, procurou fornecer uma resposta para a necessidade de melhoria da eficiência ao criar o CNJ. Esse tem por objetivo realizar um controle administrativo e financeiro de todos os tribunais brasileiros, inclusive os tribunais superiores. No entanto, uma breve consulta à literatura já permite identificar a existência de uma lacuna de investigação sobre a participação do CNJ nesse ambiente institucional. Apesar de atuar sob um enfoque organizacional, ressalta-se que um olhar político e institucional da atuação do conselho ainda não foi devidamente explorado por estudos das áreas de Ciência Política e Administração Pública, mesmo quando o enfoque recai sobre a gestão do Poder Judiciário (VIEIRA; PINHEIRO, 2008; NogUeIRA, 2011; SAdek; Oliveira, 2012; OliveIRA; Nogueira, 2017). Poucos trabalhos chegam a identificar o contexto político nesse novo cenário do Judiciário (FRAGALE FILHo, 2010; SANTOS; DA Ros, 2008). O campo do Direito, por exemplo, analisava o papel do CNJ por um viés jurídico (constitucional), demonstrando aspectos favoráveis ou limitantes da atuação como órgão de controle do Judiciário (FALCÃo, 2009; FALCÃo; OLIVEIRA, 2013).

O enfoque da eficiência é fundamental para o bom funcionamento do Judiciário. A Justiça Estadual, por exemplo, apresenta o maior volume de processos e é vista como o segmento do Poder Judiciário que tem o pior nível de atuação. Trata-se de 
um reflexo direto de ser demandado pela população (FALCÃo, 2009; DEPARTAMENTO DE Pesquisas JudiciáriAs, 2012b, 2013, 2014, 2015, 2016). No entanto, alguns estudos apontam uma grande disparidade no nível de eficiência dos tribunais quando comparados entre si (DEPARTAMENTO DE PESQUISAS JUDICIÁRIAS, 2012b, 2013, 2014, 2015; Fochezatto, 2010; Yeung, 2010; Yeung; Azevedo, 2011; Nogueira et al., 2012; FAVERI; Pereira; Oliveira, 2014). Situação que não deveria ocorrer, devido ao estabelecimento dos preceitos de uniformidade das instituições, pois os tribunais atuam sob a mesma legislação processual e possuem estrutura funcional semelhante. Essa heterogeneidade impacta a percepção popular do nível de eficiência do Judiciário, que costuma ser taxado como moroso, apesar de alguns tribunais serem eficientes. Por isso, é importante entender quais os motivos para tamanha diversidade. Seriam aspectos financeiros e orçamentários? Ou seria a diferença de demanda processual? Ou quem sabe a quantidade de magistrados e funcionários? Quais as interferências causadas por agentes que não se beneficiam com a eficiência do Judiciário? De que forma o CNJ atua na redução dessas disparidades? Tais reflexões preliminares levam a questionar, de forma mais ampla, se um Judiciário eficiente interessa realmente a todos.

As justificativas para o recente movimento de melhoria dos indicadores de desempenho do Judiciário são limitadas. Portanto, o presente trabalho consiste em uma tentativa de descrever o estado da arte da literatura existente e, a partir daí, propor novas direções para futuras pesquisas.

Este trabalho está estruturado da seguinte forma: a seção 1 constitui-se desta introdução. A seção 2 procura trazer uma reflexão teórica sobre a gestão do Poder Judiciário, abordando as reformas administrativas e o cenário político-institucional. A seção 3 apresenta uma breve descrição do funcionamento do Judiciário e do recente contexto histórico brasileiro. O planejamento estratégico e as metas anuais são abordados na seção 4 . A seção 5 realiza uma reflexão crítica sobre o enfoque administrativo, destacando a avaliação de desempenho e a busca pela eficiência dos tribunais. Por fim, são apresentadas as considerações finais e encaminhamentos para futuras pesquisas.

\section{Reflexões teóricas sobre gestão do Judiciário}

Dada a tripartição de poderes do Estado, o Judiciário possui algumas peculiaridades que tornam os elementos de seu funcionamento bem distintos em relação ao Executivo e ao Legislativo (MONTESQUiEU, 1962). A atuação do Judiciário geralmente é representada na figura dos magistrados (juízes), pois são os detentores do ato de julgar e dirimir conflitos entre as partes envolvidas (litigantes). Na atividade judicial moderna, por exemplo, é possível identificar três 
princípios básicos, decorrentes do Estado de Direito liberal, que, em certa medida, continuam vigentes. O primeiro consiste em que o magistrado se pronuncie apenas quando for acionado. Isto demonstra a passividade do Judiciário, fazendo com que o magistrado não se manifeste enquanto não for acionado e muito menos fora dos autos (processos judiciais), como uma demonstração de garantias processuais e imparcialidade dos julgamentos. O segundo ponto é inerente ao primeiro, pois o magistrado apenas se manifesta sobre casos concretos. Portanto, há a necessidade de um litígio para o seu envolvimento. Em outras palavras, o magistrado necessita de um caso concreto e formalizado de conflito entre partes diante da lei para que ele exerça a sua atividade profissional. E por último, o magistrado pronuncia-se sobre casos particulares. A atuação dele é restrita ao julgamento das particularidades e não trata sobre questões ou princípios gerais. Caso a decisão do magistrado atinja um princípio geral, a impotência do juiz pode ser evidenciada. Ao contrário, manifestando-se num princípio geral sem qualquer caso particular, o magistrado acaba exercendo uma atribuição que não é essencialmente sua (ARANTES, 1997; TOCQUEVILLE, 1998). Os princípios anteriores representam a tentativa de afastar os magistrados e os tribunais da esfera política, objetivando ao máximo a manutenção da imparcialidade das decisões (ARANTES, 1997). Por outro lado, é necessária uma gestão adequada para o Judiciário não ficar enfraquecido nesse contexto institucional, pois o seu bom funcionamento é essencial para a sociedade.

O Judiciário apresenta um papel importante ao ser essencialmente conservador, reforçando a manutenção do status quo (TAYLOR, 2008). Atua como um garantidor da aplicabilidade da legislação, portanto representa a execução plena das regras previamente estabelecidas, denominadas como as regras das leis (MARAvalL; PRZEWORSKI, 2003). Paralelamente, é possível identificar também um papel econômico, relacionado com as garantias de cumprimento dos contratos. A análise econômica do Direito demonstra que as leis são fundamentais para o bom funcionamento dos mercados e influenciam no cenário institucional junto aos custos de transação (PINHEIRO, 2003; YEUNG, 2010).

Apesar dessas demonstrações de importância e da indicação de diferenças entre os poderes constitucionais, a prestação do serviço jurisdicional segue o modelo de gestão similar a outros órgãos e esferas da administração pública. Portanto, é possível identificar facilmente os elementos recorrentes de um modelo de gestão burocrático, como, por exemplo, a divisão de tarefas, uma estrutura permanente, uma estrutura de carreira, a prestação de serviços em larga escala, entre outros aspectos (GRAHAM JR., 1993). Porém, Dubois e Boyum (1993) observam que o crescimento populacional, o desenvolvimento econômico, a urbanização e a industrialização dos últimos séculos produziram um aumento exagerado no volume e na complexidade dos casos judiciais e que os tribunais não estavam devidamente 
preparados para gerenciá-los. O despreparo do Judiciário fica ainda mais evidente quando a falta de gestão serve como estímulo para a obtenção de vantagens para determinados grupos. Taylor (2008) e Taylor e Da Ros (2008) procuram demonstrar como os atores políticos utilizam-se de mecanismos jurídicos para interferir em políticas públicas ou no próprio sistema político em si. Eles buscam alcançar quatro objetivos: atrasar (delay policy), anular (disable policy), descreditar (discredit policy) ou declarar oposição (declare opposition). Tais estratégias são frequentemente utilizadas pelos agentes devido a três motivos: todas as alternativas anteriores de interferência falharam; os custos judiciais não são compreendidos como altos; e o mecanismo jurídico é o último desafio, que pode gerar uma inesperada vitória legal.

Os aspectos apresentados anteriormente reforçam os argumentos de que o Judiciário tende a representar o conservadorismo e é caracterizado tradicionalmente pela inércia. Consiste num poder compreendido e lembrado pela sociedade como a última instituição que pode reconhecer os seus direitos, mas essa mesma sociedade é extremamente prejudicada pela morosidade em suas decisões. Essa lentidão faz com que os custos econômicos e financeiros sejam aumentados, enquanto a percepção de eficiência e, consequentemente, de justiça é extremamente diminuída (GRAHAM JR, 1993; SADEK, 2004; FALCÃO, 2009). A recorrência desse cenário faz com que os problemas não fiquem restritos ao caráter financeiro ou político, pois demonstram dificuldades de cunho administrativo. Há uma necessidade evidente de realização de ajustes, mudanças de cunho institucional que procuram reduzir a lacuna entre a demanda social e a satisfação dessa demanda (DUBOIs; Boyum, 1993). A generalização dessa insatisfação com a prestação dos serviços públicos faz com que o desejo de mudança fique mais forte. A profundidade da mudança necessária é que leva à formação de uma reforma. Um processo de reforma ocorre, principalmente, quando se busca uma política de mudança. Do mesmo modo que outras reformas (reforma fiscal, reforma educacional, reforma tributária, por exemplo), a reforma no Judiciário é fundamentada pela vontade do governo de propor uma nova atitude (Boyum, 1987). Portanto, o conceito de reforma não é apropriado para descrever novos projetos ou novas construções, mas sim aquilo que se verifica como mudanças estruturais ou inovadoras na prestação dos serviços públicos.

O ambiente de reformas na gestão pública emergiu com vigor na Grã-Bretanha e nos Estados Unidos por meio de governos que adotaram práticas neoliberais. $\mathrm{O}$ principal ponto a ser alcançado consistia na introdução de um enfoque gerencial visando alcançar melhores níveis de eficiência. No entanto, em alguns casos, a tendência neoliberal fazia com que se buscasse apenas a redução dos gastos e não propriamente a eficiência. Em seguida, outros países também aderiram a processos 
semelhantes de reformas, como, por exemplo, a Austrália, a Nova Zelândia e a Suécia. Os serviços públicos dos países que passaram pela reforma perderam gradativamente os traços burocráticos e adquiriam características gerenciais (FAirbrother, 1994; Pollit, 1990; BRESSER-PEREIRA, 1998).

As mudanças não ficaram restritas aos Poderes Executivo e Legislativo. $\mathrm{O}$ Judiciário também necessitava de mudanças profundas, o que resultou no enfoque da administração judicial (GALLAS, 1979). A modernização da agenda dos tribunais (no caso, tribunais norte-americanos) pode ser resumida em alguns elementos básicos: 1) consolidação, simplificação e padronização das estruturas dos tribunais; 2) centralização dos sistemas de gerenciamento dos tribunais; 3) centralização das regulamentações internas e procedimentos padronizados; 4) centralização orçamentária; 5) financiamento completo das atividades realizadas pelas próprias unidades judiciais; 6 ) estruturas formais e procedimentos para disciplinar e remover magistrados por improbidades e imperícias; 7) a adoção de critérios baseados em mérito para a seleção e promoção dos magistrados. Portanto, os cinco primeiros elementos podem ser compreendidos como um processo de centralização do gerenciamento dos tribunais, enquanto os dois últimos representam os esforços para uma maior profissionalização dos serviços visando à eficiência (BERKSON; CARBON, 1978; GLICK, 1988).

As considerações levantadas anteriormente são apresentadas como um panorama do Judiciário, mas podem ser enquadradas e contextualizadas quando se visualiza o cenário brasileiro. Assim como os demais países, o Brasil também passou por reformas. Porém, a gestão do Judiciário ainda carece de maior visibilidade no campo de estudos de Administração Pública no Brasil. O estudo de Nogueira (2011) demonstra que a temática não representa nem 1\% dos artigos publicados nos principais periódicos e anais de eventos da área de Administração Pública do Brasil. De forma complementar, o estudo de Oliveira e Nogueira (2016) aponta um incremento de pesquisas após a coleta e divulgação de dados sobre o Judiciário realizadas frequentemente pelo CNJ. O referido órgão é recorrentemente apresentado como o principal exemplo da mudança de abordagem ocorrida no Poder Judiciário brasileiro. É importante perceber como o Judiciário adquiriu mais espaço no cenário institucional ao ter um papel mais participativo nas políticas públicas do país. Essas, anteriormente restritas ao Executivo e Legislativo, ganham um maior engajamento do Judiciário em campanhas com cunho social, como, por exemplo, relacionadas à defesa da mulher, à adoção, aos direitos humanos, à melhoria do sistema prisional, improbidade administrativa e crimes contra a administração pública, entre outros assuntos (TAYLOR, 2007; SILVA; FLORÊNCIO, 2011; BARBozA; KozICKI, 2012; SAUERBRonN; Lodi, 2012; Oliveira, 2013). 


\subsection{A Reforma do Judiciário no Brasil e perspectivas de pesquisas em gestão}

O Poder Judiciário brasileiro passou a receber um grande aumento de demanda principalmente nas décadas de 1990 e 2000. A intensificação da procura pelos serviços judiciais foi um reflexo da ampliação da garantia de direitos fundamentais individuais e coletivos e da possibilidade de contestação da inconstitucionalidade das leis por novos atores, igualmente conferida pela Constituição Federal (CF) de 1988. O Judiciário ganha um novo papel com a Constituição, sendo protagonista de uma oportunidade de ampliação de seu poder político, dada a ampliação da prestação de seus serviços. Além disso, foram visualizados dois movimentos simultâneos: de um lado, uma politização do Judiciário, e, em reverso, uma judicialização da política (ARANTES, 1997; Rodovalho, 2012; SAdEK, 1999, 2004).

Após a CF, o aumento da demanda foi superior à capacidade de processamento e resolução das causas judiciais por parte dos tribunais no país, não correspondendo plenamente os seus serviços. Evidenciou-se a necessidade de pensar estrategicamente e desenvolver uma estrutura gerencial que permitisse lidar adequadamente com os problemas e dificuldades acumulados ao longo de muitos anos. Tal situação ficou conhecida como "a crise do Judiciário" (MOTTA, 2010; NogueIRA, 2010). Como foram vistos avanços gerenciais nos Poderes Executivo e Legislativo após a reforma administrativa proposta pela Emenda Constitucional $n$ ㅇ 19/1998, que reforçava o gerencialismo na administração pública e evidenciava a introdução da eficiência como um dos princípios constitucionais, algumas soluções para a tal crise do Judiciário foram levantadas (BRESSER-PEREIRA, 1996, 1998, 1999). Desse modo, a adoção de práticas de gestão no Judiciário brasileiro foi gradativamente ganhando força e sendo empregada por alguns dos principais tribunais do país, enquanto a ideia de reforma continuava sendo discutida (FundaçÃo GETÚlIo VARGAS, 2005; GonçALVES, 2007a, 2007b).

A Reforma do Judiciário ocorreu apenas no final de 2004, por meio da Emenda Constitucional no 45/2004. Ela permitiu a criação de um ambiente de novas ideologias e práticas relacionadas à gestão, principalmente com a criação do CNJ. Portanto, é criado um órgão que tem como principal objetivo realizar o controle administrativo e financeiro do Judiciário brasileiro (NogUeIRA, 2010; RodovalHo, 2012; VIEIRA; PINHEIRO, 2008). Porém, a emenda na Constituição não criou apenas a figura do CNJ, mas também realizou outras mudanças, como, por exemplo, a criação do Conselho Nacional do Ministério Público (CNMP), as escolas nacionais de magistraturas, os institutos da Súmula Vinculante e da Repercussão Geral e, ainda, ampliou a competência da Justiça do Trabalho. As mudanças também foram sentidas nos outros Poderes constitucionais. O estabelecimento de um Pacto Republicando, em 2005, permitiu a aprovação dos parlamentares de projetos de lei conjuntos que visavam um Judiciário mais célere e republicano (FALCÃo, 2009). 
O CNJ tem se movimentado para melhorar o desempenho judicial, trabalhando estrategicamente e desenvolvendo sistemas de monitoramento e divulgação de dados sobre o Judiciário (CONSELHO NACIONAL DE JUSTIÇA, 2006, 2009a; Departamento de PesquisAs JudiciáriAs, 2011a, 2011b, 2012a, 2012b, 2013, 2014, 2015). Visando à manutenção da independência e autonomia, o CNJ tem abordado questões polêmicas para o serviço público, como, por exemplo, o combate ao nepotismo, a restrição da quantidade de servidores cedidos de outros poderes, o combate à corrupção, a alteração das regras de promoção dos magistrados na carreira, entre outros aspectos (CONSELHO NACIONAL DE JUSTIÇA, 2005, 2009b, 2010, 2013b; OLIVEIRA, 2013).

São reconhecidos os avanços realizados pela Reforma do Judiciário no Brasil, mas é importante ter em vista a existência de críticas quanto aos resultados alcançados ao longo dessa década de atuação. Essas críticas servem como possíveis caminhos de construção do conhecimento e, portanto, servem como pontos de partidas para temas a serem explorados e aprofundados. Rodovalho $(2012,2014)$ não percebe a Reforma do Judiciário (EC no 45/2004) como um processo de continuação ou consequência da Reforma Administrativa (EC no 19/98). A argumentação recai na ideia de que mudanças profundas no Judiciário já eram discutidas desde 1992, portanto, cronologicamente antes da primeira reforma na administração pública. Além disso, os enfoques de atuação eram distintos, dado que o enfoque de redução da burocracia e de custos na administração pública não foram motivadores para a busca por uma Justiça mais célere. A ideia é de que é necessário ir além da relação do CNJ e dos tribunais na busca pela eficiência do Judiciário (RodovalHo, 2012, 2014). Esse ponto assemelha-se ao entendimento de que a Reforma do Judiciário impactou, principalmente, o Supremo Tribunal Federal (STF) e de que há a necessidade de uma nova reforma. O STF conseguiu se beneficiar com os institutos da Repercussão Geral e da Súmula Vinculante, fazendo com que diminuísse a demanda por seus serviços e dando agilidade a um maior número de julgamentos (FALCÃO; CERDEIRA; ARGUELHES, 2011; FALCÃo et al., 2013; FALCÃo; HARTMANN; CHAVES, 2014). No entanto, não tem acontecido movimento similar nos outros tribunais (DEPARTAMENTO DE PESQUISAS JUDICIÁRIAS, 2013). Este, por exemplo, é um ponto que precisa ser mais investigado e compreendido: então os resultados da Reforma foram limitados?

Há, também, a visão de que a Reforma do Judiciário não ficou restrita aos tribunais, aos magistrados e servidores. O impacto dela pode ser sentido em todos os envolvidos com o sistema da Justiça brasileira. É importante olhar os papéis dos diferentes agentes dentro desse sistema, como, por exemplo, advogados, promotores, defensores públicos, políticos e as entidades representativas de classes (Ordem dos Advogados do Brasil (OAB), associações de magistrados, associações 
de servidores, partidos políticos, entre outras) (ARANTES, 2002; TAYLOR, 2008; Taylor; Da Ros, 2008; Fragale Filho, 2010; FaVeri; Pereira; Oliveira, 2014; Falcão; MORAES; HARTMANN, 2015).

\section{O Judiciário e o recente contexto histórico brasileiro}

Ao lidar com assuntos relativos à sua gestão, o Poder Judiciário brasileiro sempre careceu de mecanismos que permitissem um conhecimento mínimo de sua organização administrativa. Até meados da década de 2000, era difícil conseguir responder de forma mais precisa alguns questionamentos que envolvessem a quantidade de magistrados ou de servidores, a contagem de casos (processos) novos ou de casos finalizados, o orçamento dos tribunais, entre outros dados básicos à administração de uma instituição de tal porte (SADEK, 2004; NOGUEIRA et al., 2012). Na tentativa de tratar esse problema, o movimento de coleta de dados gerenciais começou por frentes distintas. Houve esforços para coletar desde dados mais agregados até dados mais individualizados, bem como para a identificação dos maiores demandantes e demandados da prestação jurisdicional (chamados tecnicamente de litigantes).

A partir de 2006, o CNJ passa a recolher e sistematizar dados estatísticos referentes a aspectos ligados ao desempenho das organizações judiciárias brasileiras. Os dados, após tratamento estatístico, eram apresentados em forma de indicadores agrupados em áreas como: insumos, dotações orçamentárias, litigiosidade e acesso à justiça (CONSELHO NACIONAL DE JUSTIÇA, 2006; Departamento de Pesquisas Judiciárias, 2012b, 2013, 2014, 2015, 2016). Esses dados são divulgados por intermédio do relatório anual intitulado Justiça em Números. Os dados são considerados agregados, pois retratam a situação consolidada dos tribunais. Há subdivisões por competência e jurisdição em nível macro (2 Grau; 1ㅇ Grau; Turmas Recursais, Juizados Especiais), mas os dados não refletem a situação de segmentos da justiça ou das unidades judiciárias de forma isolada (Departamento de PEsquISAS JUdICIÁRIAS, 2012b, 2013, 2014, 2015, 2016; NogueIRA et al., 2012).

Pensando na formação de um banco de dados que contemplasse questões mais relativas a um nível micro, o CNJ desenvolveu o programa Justiça Aberta no final de 2007. Trata-se de um programa gerenciado pela Corregedoria Nacional de Justiça que permite fornecer elementos maiores de transparência, facilitando o acesso à justiça. O sistema Justiça Aberta apresenta dados tanto das serventias judiciais (1ㅇ e 2o grau), como das extrajudiciais (cartórios), mas apenas referese à competência da Justiça Estadual, também conhecida como justiça comum. Castro (2011) ressalta a importância dessa base por fornecer dados desagregados 
em relação ao relatório Justiça em Números, permitindo servir como um melhor instrumento para análise e formulação de políticas judiciárias considerando o cunho regional inserido na esfera global.

A principal justificativa consiste na existência de uma heterogeneidade do Judiciário brasileiro. Assim, o Justiça Aberta analisa de forma mais detalhada a evolução mensal das deficiências e virtudes de cerca de nove mil unidades jurisdicionais espalhadas por todo o país. O nível de detalhamento fornece informações como: o número de funcionários, o estoque de processos pendentes, o volume de despachos e decisões interlocutórias, a quantidade de processos distribuídos e resolvidos (sentenças e acordos homologados). Vale ressaltar que esse programa divulga variáveis ainda pouco exploradas nas pesquisas recentes (GOMES; GUIMARÃES, 2013).

Um levantamento complementar ao programa Justiça Aberta foi proposto pelo CNJ como uma ação estratégica para o ano de 2010. Consistia na identificação e publicação dos maiores litigantes, no caso, as organizações que mais demandam do Judiciário, tanto no polo ativo como no polo passivo. Para tanto, foram publicados, até o momento, duas edições do relatório 100 maiores litigantes. A primeira apresenta as maiores organizações que possuem processos ainda não baixados definitivamente até 31 de março de 2010. Portanto, apresenta um recorte da quantidade acumulada de processos vigentes segmentados conforme a sua distribuição nos tribunais estaduais, federais e trabalhistas (DEPARTAMENTO DE PESQUISAS JUDICIÁRIAS, 2011b). A segunda edição, por sua vez, procura fazer uma atualização desses dados, mas levando em consideração apenas os processos novos que foram acrescentados aos acervos processuais até 31 de outubro de 2011 (Departamento de Pesquisas JudiciáriAs, 2012a). As duas edições apresentavam a relação de forma individualizada (indicando o nome da organização) e de forma agregada por setor (divididos, por exemplo, em: bancos, indústrias, serviços, setor público municipal, setor público estadual, setor público federal, entre outros). 0 principal objetivo desse instrumento era identificar os maiores demandantes do Judiciário para, com isso, propor ações e políticas que permitissem a redução do volume de processos. Há também a ideia de realizar diálogos institucionais que busquem propor ações nas quais o Judiciário seja demandado de forma mais equilibrada e somente quando não houver mais mecanismos internos (administrativos e extrajudiciais) para a resolução de conflitos. Ficou evidenciado, nos dois relatórios, que os setores públicos (nos três níveis governamentais) são os maiores litigantes da Justiça Estadual, sendo, portanto, um forte elemento no congestionamento dos tribunais. 
Os relatórios apresentados anteriormente reforçam os argumentos que buscam promover uma maior transparência por parte da atuação do Poder Judiciário brasileiro. Além disso, os dados provenientes de documentos e banco de dados públicos permitem a geração de diferentes análises para uma melhor compreensão da realidade e formulação de políticas públicas. Em geral, os dados desses relatórios vêm sendo utilizados para tratar da medição e avaliação do desempenho obtido pelo Poder Judiciário no Brasil. A grande questão que envolve os relatórios aqui apresentados (Justiça em Números, Justiça Aberta e 100 Maiores Litigantes) é a busca por tornar o Judiciário mais célere, mais eficiente e, se possível, com a redução dos custos envolvidos. Os levantamentos de dados serviram, também, para que o CNJ coordenasse o processo de planejamento estratégico do Judiciário brasileiro. Dessa forma, objetivos e metas foram propostos para gerar um acompanhamento dos avanços realizados para uma melhor prestação dos serviços judiciais.

\section{O planejamento estratégico e as metas do Judiciário brasileiro}

A adoção de ferramentas de planejamento estratégico já era colocada em prática por alguns tribunais antes mesmo da existência ou manifestação do CNJ nesse sentido. O enfoque gerencial da Administração Pública fez com que a estratégia fosse vista pelos tribunais com a ideia de reforma ou de construção de um novo tribunal (FundAção Getúlio VARGAS, 2005; GonÇALVES, 2007a; 2007b). Destaca-se o papel da institucionalização de órgãos de assessoria ou secretarias voltados especificamente para a questão do planejamento estratégico nos tribunais (Azevedo, 2010; MARANHÃo, 2005; Morey Filho; CrÉdico, 2007; OLIVEIRA; PONTES; SOARES, 2014). O desenvolvimento de planejamento estratégico tinha um caráter mais pontual e não era algo formalmente adotado por todas as gestões. Era necessário um processo de centralização e alinhamento, algo que poderia ser coordenado pelo CNJ. Portanto, depois da sistematização que permitiu uma recorrente coleta de dados sobre os tribunais, o CNJ partiu para o passo seguinte de definição da estratégia do Judiciário brasileiro. As principais inspirações do CNJ foram os trabalhos realizados pela Commission Européenne pour l'Efficacité de la Justice (Cepej) (NogueIRA, 2010) e, por outro lado, a adoção dos mapas estratégicos do Balanced Scorecard (BSC) (KAPLAN; NORTON, 2004; AZEVEDo, 2010).

A primeira influência consiste em um conselho ligado ao Conselho da Europa que procura desenvolver a eficiência e a melhoria do funcionamento dos sistemas judiciais dos países membros. Os trabalhos realizados pelo Cepej assemelhamse aos do relatório Justiça em Números, porém vão além, com a realização de análises contextuais e de debates quanto aos desafios entre as particularidades dos 
diferentes sistemas judiciais com a integração em âmbito continental (COMMISSION EUROPÉENNE POUR L'EFFICACITÉ DE LA JUSTICE, 2008; NogUeIRA, 2010). Enquanto isso, a ideia de mapas estratégicos e da adoção do BSC possibilitou a definição da missão, visão e dos atributos de valor do Judiciário brasileiro. A adoção dessa metodologia permitiu estabelecer objetivos estratégicos e mensurá-los a partir das quatro dimensões do modelo: aprendizado e crescimento; clientes; processos internos; e financeira (KAPLAN; Norton, 2004; AZEVEdo, 2010). Dessa forma, os objetivos eram desdobrados em metas. As metas eram alcançadas por meio de projetos, que necessitavam da alocação de recursos para sua devida implementação. Porém, eram necessários também procedimentos de alinhamento e nivelamento com todos os tribunais (VIEIRA; PINHEIRO, 2008; MANZINI, 2010).

A partir de 2009, os trabalhos de alinhamento e nivelamento foram iniciados com o estabelecimento de metas nacionais, que eram ligadas, no mínimo, a um dos objetivos estratégicos. A ideia central consistia em atribuir metas que deveriam ser cumpridas no próprio ano em que foram estabelecidas. As metas eram sugeridas pelo CNJ, e votadas e aprovadas pelos presidentes de todos os tribunais do país durante os encontros anuais do Judiciário. Esse era um evento realizado sempre no ano anterior, facilitando a divulgação e o conhecimento das metas para os trabalhos a serem realizados desde o início do ano. O CNJ, com esses procedimentos, reforçava os aspectos de centralização e uniformização do Judiciário (BERKSON; CARBON, 1978; GLICK, 1988), além de operacionalizar o conceito do BSC com as medições periódicas do alcance das metas (KAPLAN; NORTON, 2004; CUNHA, 2010). A implantação do BSC nos tribunais contou com a participação de uma consultoria e, inclusive, foi a Meta 1 do ano de 2009 (AZEVEdo, 2010; Conselho NACionAl DE JUStIÇA, 2010; GANGEMI; FERNANDES, 2010).

Os aprendizados gerados pelas metas nos dois primeiros anos (2009 e 2010) foram fundamentais para mudança de rumos nos anos posteriores. A falta de cumprimento da maioria das metas por parte dos tribunais foi objeto de seguidas críticas por parte da imprensa. Algumas metas eram muito desafiadoras, demonstrando a fragilidade do Judiciário para a sua plena implementação (CONSELHO NACIONAL DE JUSTIÇA, 2010, 2011). O CNJ estava criando um grave problema de mensuração de produtividade. Ocasionou um aumento de medição de informações nos tribunais, que inicialmente não estavam devidamente preparados, além de possuírem indicadores focados no curto prazo (BOUCKAERT; BALK, 1991; FRAGALE FILHO, 2007).

Algumas mudanças foram propostas pelo próprio CNJ para retomar adequadamente o foco estratégico, a saber: definição de metas por segmentos do Judiciário (por exemplo, a Justiça Estadual poderia ter metas diferentes da Justiça Eleitoral); redução da quantidade de metas (não havia mais a obrigatoriedade 
de ter dez metas por ano); antecipação da divulgação de metas para os anos seguintes (divulgava as metas do biênio posterior), facilitando a garantia de busca de recursos orçamentários que seriam vinculados diretamente a projetos de cumprimento das metas; foco nas metas não cumpridas em anos anteriores e reconhecimento pelo cumprimento (visava garantir a continuidade dos esforços e reconhecia os méritos das unidades judiciais que conseguiam o cumprimento). Essas mudanças foram fundamentais para aumentar o nível de cumprimento, mas ainda cabe investigar o papel do CNJ com questões estratégicas que estejam diretamente ligadas à prática social, tanto na perspectiva institucional, quanto de forma segmentada, a partir dos olhares dos servidores e magistrados (SAUERbronn; SAUERbronn, 2015; SAUERbronn; Lourenço, 2016; SAUERBronn et al., 2016). Portanto, é necessário investigar como criar um ambiente mais favorável para o alcance das metas, mas mantendo o perfil desafiador perante os problemas do Judiciário e da sociedade, como, por exemplo, o combate à corrupção (AGÊNCIA BRASIL; 2012; CONSELHO NACIONAL DE JUSTIÇA, 2013a; 2013b; OLIVEIRA, 2013). O CNJ precisa retomar a credibilidade e o papel de protagonista nas mudanças do Judiciário (FALCÃO; OlıVEIRA, 2013). Porém, há espaços para um olhar mais descentralizado do cenário, atentando-se para as diferenças locais e abrindo espaço para o surgimento de novas visões na busca por um maior nível de eficiência nos tribunais.

\section{A mensuração do desempenho e o enfoque na eficiência}

Os aspectos relativos a bens e serviços públicos tendem a ser considerados de difícil mensuração e avaliação. No entanto, tende-se a utilizar indicadores intermediários para medir aspectos organizacionais ou individuais (LEVITT; JOYCE, 1988). Gomes e Guimarães (2013) construíram um ranking das dimensões de desempenho mais abordadas nos artigos publicados entre anos de 1992 e 2011 em base de dados de publicações internacionais, bem como em artigos apontados nas referências dessas publicações. A dimensão de eficiência foi apresentada em cerca de $94 \%$ dos estudos, destacando o indicador da taxa de resolução de processos. As outras dimensões encontradas foram: celeridade, independência, efetividade, acesso e qualidade, conforme apontado no Quadro 1. Percebe-se que há um aumento dessa temática a partir do ano de 2009 (GOMES; GUIMARÃES, 2013). O incremento de estudos sobre gestão estratégica e desempenho organizacional pode ser compreendido a partir da introdução de mecanismos de mensuração de desempenho por parte do CNJ, tal qual já anteriormente sinalizado pelo estudo de Nogueira (2010). 
Quadro 1 - Dimensões, categorias e variáveis de desempenho utilizadas nos estudos revisados

\begin{tabular}{|c|c|c|}
\hline $\begin{array}{l}\text { Dimensão de } \\
\text { desempenho }\end{array}$ & $\begin{array}{c}\text { Principal categoria } \\
\text { de interesse }\end{array}$ & Principais variáveis utilizadas \\
\hline Eficiência & Produtividade & $\begin{array}{l}\text { - } \text { Quantidade de processos concluídos } \\
\text { - } \quad \text { Quantidade de sentenças proferidas }\end{array}$ \\
\hline Celeridade & Duração de processos & $\begin{array}{l}\text { - Tempo de trâmite de procedimentos } \\
\text { judiciais } \\
\text { - Tempo de trâmite de procedimentos } \\
\text { administrativos }\end{array}$ \\
\hline Efetividade & Confiança & $\begin{array}{l}\text { - Quantidade de violações aos direitos } \\
\text { humanos } \\
\text { - } \quad \text { Quantidade de processos de } \\
\text { corrupção }\end{array}$ \\
\hline Qualidade & Mérito de decisões & $\begin{array}{l}\text { - } \quad \text { Quantidade de decisões publicadas } \\
\text { - } \quad \text { Quantidade de decisões reformadas }\end{array}$ \\
\hline Independência & Autonomia & $\begin{array}{l}\text { - Quantidade decisões contrárias ao } \\
\text { governo } \\
\text { Quantidade de recursos financeiros } \\
\text { alocados }\end{array}$ \\
\hline Acesso & Abrangência & $\begin{array}{l}\text { - } \quad \text { Quantidade de juízes per capita } \\
\text { - } \quad \text { Quantidade de pessoas atendidas }\end{array}$ \\
\hline
\end{tabular}

Fonte: Gomes e Guimarães (2013, p. 387).

A eficiência é demonstrada por meios técnicos e pelos seus aspectos econômicos. Alguns estudos buscam evidenciar os impactos econômicos do Judiciário, bem como as possibilidades de redução dos custos dos processos. A ideia básica é de que um Judiciário eficiente, eficaz e efetivo serve como estímulo para o desenvolvimento da economia, bem como garantia de que eventuais embates jurídicos sejam adequadamente resolvidos e não prejudiquem a intenção de futuros investimentos financeiros. Tais estudos estão inseridos no contexto da Análise Econômica do Direito, ou do Law and Economics, um movimento que surgiu na década de 1960 nos Estados Unidos. Maiores informações sobre o assunto podem ser encontradas nos estudos desenvolvidos por Sherwood, Shepherd e Souza (1994), Castro (2002) e, de forma mais detalhada, em Yeung (2010).

Os mecanismos de análise foram divididos em quatro dimensões ou escopos, a saber: individual, grupal, organizacional e institucional (GOMES; GUIMARÃES, 2013). No primeiro nível, os estudos focavam a produtividade individual dos magistrados, 
compreendidos como os atores centrais do Judiciário. No nível grupal, as análises eram realizadas ao investigar o desempenho de comarcas, distritos ou do grupo de magistrados de diferentes unidades judiciais, mas de uma mesma competência de atuação. O nível organizacional demonstrou ser predominante na maioria dos estudos realizados. A mensuração de eficiência de tribunais demonstrou ser mais representativa, chamando a atenção dos pesquisadores. O último nível consiste na realização de estudos que visam comparar o desempenho do Judiciário brasileiro com o de outros países. Dessa forma, o nível é sugerido como institucional, pois os judiciários nacionais tornam-se o objeto de análise.

Alguns aspectos foram abordados por Gomes e Guimarães (2013) ao realizar o levantamento desses estudos, como, por exemplo, o recorte temporal, fonte dos dados e técnicas de análise de dados. A maioria dos trabalhos utilizou um recorte transversal, alguns poucos fizeram uma pesquisa transversal com uma perspectiva longitudinal (ao adicionar mais de um ano nas análises realizadas). A fonte de dados principal foi secundária, em sua grande maioria utilizando os dados provenientes do relatório Justiça em Números. Entre as técnicas de análise, a análise estatística de regressão predominou, embora tenham sido percebidos avanços com a utilização da técnica de análise envoltória de dados (DEA, sigla em inglês para Data Envelopment Analysis). Essa técnica foi utilizada inicialmente para estudos do Judiciário em 1982, mas ganhou destaque por permitir a comparação de coeficientes de eficiência relativa entre diferentes unidades. No caso, ao verificar a eficiência dos tribunais, demonstrou-se adequada aos estudos do Judiciário (GOMES; GUIMARÃES, 2013; LEWIN; MOREY; COOK, 1982).

Os aspectos anteriores servem como ponto de partida para algumas considerações críticas. Além disso, são apontados alguns estudos que não foram indicados por Gomes e Guimarães (2013). Complementa-se, a seguir, o levantamento e assinalamse avanços no campo de estudo.

Sugere-se, inicialmente, a realização de mais estudos longitudinais como forma de abordar adequadamente o processo de dinâmica e transformação que vem ocorrendo nos últimos anos no Poder Judiciário. A utilização de dados provenientes dos bancos de dados e relatórios do CNJ serve como estímulo para a realização de estudos longitudinais. O relatório Justiça em Números, por exemplo, já poderia permitir uma análise mais aprofundada, se não tivessem ocorrido alterações nas variáveis coletadas pela Resolução no 76 no ano de 2009 (CONSELHO NACIONAL DE JUSTIÇA, 2009a). Tal fato pode ser percebido ao se verificar que os estudos têm se utilizado de dados provenientes do Justiça em Números até o ano de 2008 (Fochezatto, 2010; Nogueira et al., 2012; Yeung; Azevedo, 2011), assim como o que utilizou dados do sistema Justiça Aberta (CASTRO, 2011). Esses dados eram 
coletados tendo como base a Resolução no 15 do ano de 2006, por sinal, a resolução pioneira do CNJ que visava estruturar o Sistema de Estatística do Poder Judiciário (SIESPJ) (CONSELHO NACIONAL DE JUSTIÇA, 2006).

Os avanços encontrados a partir da edição do Justiça em Números 2013 podem ser compreendidos como um olhar do CNJ aos estudos acadêmicos realizados nos últimos anos. A perspectiva longitudinal foi levada em consideração, pois utilizam para efeito de comparação os dados referentes aos anos de 2009 a 2012. Todos esses dados, conforme as orientações da resolução vigente (CONSELHO NACIONAL DE JUSTIÇA, 2009a; Departamento de Pesquisas Judiciárias, 2013). Além disso, o relatório incorporou a DEA, criando o Índice de Produtividade Comparada da Justiça (IPC-JUS). Esse promove um ranking de eficiência técnica entre os tribunais. Dessa forma, pode-se reconhecer se o desempenho do tribunal melhorou ou piorou ao longo desses anos, permitindo informações para futuras tomadas de decisão que promovam uma melhoria no desempenho dos tribunais. Essa ideia já vem sendo colocada em prática por um tribunal estadual. Investiu-se na produção do Sistema de Apoio à Decisão (SAD) baseado na DEA, para o acompanhamento da eficiência de suas unidades judiciais. É interessante perceber que o sistema desenvolvido procura unificar as características principais do Justiça em Números e do Justiça Aberta, pois utiliza a DEA em nível micro, permitindo produzir relatórios mensais para avaliar o grau de eficiência técnica das unidades e dos magistrados, divididos por critérios de competência e jurisdição. O sistema desenvolvido é aparentemente pioneiro no Judiciário brasileiro e ainda auxilia nos procedimentos de apuração da produtividade dos magistrados que buscam a promoção na carreira (MEREILES, 2012; OLIVEIRA et al., 2016).

Questões relacionadas à avaliação dos magistrados tendem a receber uma atenção especial para efeito de medição da eficiência. A prática denominada avaliação do desempenho judicial é frequentemente utilizada no Judiciário dos Estados Unidos, pois serve de parâmetro para avaliar o desempenho dos magistrados que buscam a reeleição dos seus mandatos. Dessa forma, a busca pela medição do desempenho representa mais uma forma de maior transparência, bem como transmite a ideia, perante a sociedade, de retorno dos investimentos e despesas realizados em troca de uma melhor prestação jurisdicional (DEPARTAMENTO DE PESQUISAS JUDICIÁRIAS, 2011a).

Apesar destes avanços recentes, algumas limitações ainda são encontradas e precisam ser enfrentadas pelos pesquisadores e, principalmente, pelos operadores do Direito que participam ativamente desse processo de melhoria da prestação jurisdicional. Rodovalho $(2012,2014)$ e Karasin e Rodovalho (2012) ressaltam que essa busca pela eficiência chega a ser combatida por aqueles que se utilizam da morosidade da justiça para se beneficiar. Destaca-se que a busca 
apenas pela rapidez no julgamento dos processos serve para encobrir problemas mais profundos relacionados com a atuação dos operadores do Direito e da cultura jurídica em si. Portanto, geralmente os estudos apresentam características essencialmente quantitativas, deixando de contemplar o contexto e os pontos a serem aperfeiçoados (FragALE FILHO, 2007). Embora a técnica da DEA trabalhe também com ideia de benchmarking, essa técnica pode ser complementada por estudos ou análises que utilizem ferramentas qualitativas. Pode-se buscar com mais detalhes as nuances internas que geram diferenças entre unidades judiciais semelhantes na quantidade de insumos e recursos, bem como de competência e jurisdição. Nesse ponto, podem ser realizados avanços quanto à postura de liderança e de gestão do magistrado (FAERMAN; DIPADOVA; QUINN, 1993; VIEIRA; COSTA, 2013). Pode-se analisar se há um diferencial na equipe ou se houve a adoção de algum procedimento inovador. Portanto, são perspectivas que ampliariam as percepções encontradas nos diversos estudos recentes sobre o Poder Judiciário, trazendo recursos também de outras ciências.

Os relatórios sobre os maiores litigantes, até o momento, não tem sido devidamente explorado pelos estudos, mas permite demonstrar o quanto o próprio setor público (independentemente de ser do nível municipal, estadual ou federal) apresenta-se como um dos maiores demandantes do Judiciário. O setor público é visto como um dos interessados na morosidade dos julgamentos, dada a obrigatoriedade de utilizar-se de apelações e recursos das decisões, bem como pela demora no pagamento de suas dívidas judiciais (precatórios). Além disso, retorna a discussão inicial de possíveis movimentos de judicialização da política ou politização do Judiciário quando se verificam momentos de desarmonia entre os três Poderes constitucionais.

\section{Considerações finais e encaminhamentos para futuras pesquisas}

O presente ensaio representa um esforço inicial com relação a uma maior compreensão da participação do CNJ na melhoria do nível de desempenho do Judiciário. Inicialmente, procurou destacar o papel da Reforma do Judiciário na introdução dos aspectos de gestão e suas perspectivas, apresentando as características básicas e peculiares do funcionamento desse poder. Questões como a inércia e a busca por uma maior imparcialidade das decisões foram colocadas como inerentes às atividades jurisdicionais. Por outro lado, um breve contexto histórico dos recentes movimentos ocasionados no Judiciário brasileiro após a CF 1988 permitiu evidenciar que a morosidade necessitava ser combatida.

A análise da literatura permitiu identificar os avanços, originados principalmente após a criação do CNJ, com as ideias de planejamento estratégico e utilização de 
metas voltadas à busca pela eficiência. A disponibilização dos dados por meios de relatórios oficiais serviu como ponto de partida para a realização de estudos que analisaram a eficiência relativa dos tribunais estaduais. Verificaram-se, também, algumas lacunas metodológicas e teóricas na literatura. No primeiro aspecto, notou-se a necessidade de mais estudos longitudinais e de utilização dos dados dos relatórios oficiais referentes aos anos de 2009 a 2013, que haviam sofrido alterações por uma resolução do CNJ. Isso seria um avanço em relação aos estudos de Fochezatto (2010), Yeung e Azevedo (2011) e Nogueira e outros (2012). Além disso, sugere-se a realização de estudos em nível micro que permitam avaliar o grau de eficiência técnica das unidades e dos magistrados, divididos por critérios de competência e jurisdição. Pode-se agregar, também, uma investigação que transmita a ideia de retorno dos investimentos e despesas voltados para a melhoria dos serviços, ampliando o cenário apontado por Oliveira e outros (2016) de que há diferenças internas no gerenciamento das unidades judiciais.

No segundo aspecto, verificaram-se lacunas no enfoque teórico que apontam para a necessidade de investigação sobre a participação dos diferentes atores do sistema judicial no cenário após a Reforma do Judiciário, portanto avançando no modelo proposto por Taylor (2008) e Taylor e Da Ros (2008). Merece atenção o debate voltado para a realização de uma nova reforma, problematizando, por exemplo, se os demais tribunais também foram adequadamente impactados com as mudanças ocorridas na gestão do Judiciário brasileiro. Outro ponto consiste em identificar fatores diretamente relacionados com o desempenho dos magistrados, verificando traços de liderança, gestão de recursos e de pessoas, bem como adoção de práticas inovadoras. Essa linha de pesquisa, portanto, avançaria quanto aos conhecimentos de Vieira e Costa (2013), no enfrentamento das barreiras de estrutura organizacional, na cooperação entre os magistrados (ligando as inovações aos conhecimentos tácitos e explícitos) na organização, e no aperfeiçoamento da formação.

Os encaminhamentos para a realização de futuras pesquisas apontadas neste ensaio servem para avançar no entendimento do movimento de busca pelo aumento da eficiência no Judiciário que tem sido evidenciado nos últimos anos. As reflexões propostas podem ser incorporadas a modelos que buscam evidenciar um Judiciário mais célere e efetivo. As pesquisas poderão ser realizadas utilizando tanto métodos quantitativos como qualitativos, permitindo o encontro e confrontação de mais evidências.

Com relação aos encaminhamentos técnicos, sugere-se atentar aos resultados da ferramenta apresentada por Oliveira e outros (2016), pois permite um acompanhamento mensal do desempenho das unidades judiciárias e da produtividade dos magistrados de um tribunal. Como dito anteriormente, tal sistema é pioneiro no Judiciário brasileiro, permitindo utilizar a mesma metodologia 
do indicador IPC-JUS do CNJ para verificar o nível de eficiência comparada entre cada uma das unidades judiciárias. Nesse caso, seria uma tentativa de acompanhar o desenvolvimento de forma micro, buscando um melhor resultado em nível macro. Além disso, o sistema possibilita acompanhar mais variáveis que são utilizadas nos procedimentos de promoção dos magistrados.

Outro encaminhamento prático consiste na melhoria das experiências de desdobramento dos objetivos estratégicos em projetos que possibilitam a utilização de uma metodologia de gestão de projetos. Esse tema tem ganhado espaço mais recentemente e já tem sido objeto de estudos que analisam os condicionantes de desempenho dos projetos estratégicos (PONTES; OlIVEIRA; VASCONCELOS, 2015), o alcance dos prazos dos projetos estratégicos (MENESES; OLIVEIRA; VASCONCELOS, 2016) e as lições aprendidas reportadas pelos gerentes de projetos estratégicos (SILVESTRE, 2016). Dessa forma, pode-se aperfeiçoar a elaboração de novos planos estratégicos, permitindo o alcance de novas metas e objetivos por parte dos tribunais brasileiros.

O presente estudo apresentou os diversos caminhos de envolvimento do CNJ para a melhoria da eficiência do Poder Judiciário. Porém, um diálogo entre os estudos que abordem o Judiciário, tanto do campo da administração pública como de outras ciências, é necessário para um olhar diferenciado e mais próximo da realidade empírica. Espera-se ter contribuíd o com um passo para a maior integração desses distintos, mas convergentes campos de pesquisa.

\section{Referências bibliográficas}

AGÊNCIA BRASIL. Justiça não consegue concluir processos anteriores a 2007, aponta CNJ. Folha de São Paulo, São Paulo, 31 out. 2012.

ARANTES, R. B. Judiciário e política no Brasil. São Paulo: Idesp, 1997.

PUC-SP, 2002.

Ministério Público e a política no Brasil. Sumaré-São Paulo: Idesp,

AZEVEDo, J. S. F. A implantação da gestão estratégica no Judiciário brasileiro. Brasília: Universidade Católica, 2010. Monografia (Especialização em Gestão Estratégica de Organizações com ênfase no Balanced Scorecard) - Universidade Católica de Brasília, Brasília.

BARBOzA, E. M. Q.; KozıCKI, K. Judicialização da política e controle judicial de políticas públicas. Revista Direito GV, v. 8, n. 1, p 59-85, 2012.

BERKSON, L.; CARBON, S. Court unification: history, politics and implementation. Washington: U. S. Department of Justice, Law Enforcement Assistance Administration, National Institute of Law Enforcement and Criminal Justice, 1978.

Bouckaert, G.; BALK., W. Public productivity measurements: diseases and cures. Public Productivity \& Management, v. 15, n.2, p. 229-235, 1991. 
Boyum, K. O. The politics of court reform: a review essay. The Justice System Journal, n. 12, p. 406-423, 1987.

BRESSER-PEREIRA, L. C. Da administração pública burocrática à gerencial. Revista do Serviço Público, v. 47, n. 1, p. 7-40, 1996.

Gestão do setor público: estratégia e estrutura para um novo Estado.

In: Bresser-PereiRA, L. C.; SPINK, P. Reforma do Estado e administração pública gerencial. Rio de Janeiro: Editora FGV, 1998. p. 21-38.

Reflexões sobre a reforma gerencial brasileira de 1995. Revista do Serviço Público, v. 50, n. 4, p. 5-30, 1999.

CASTRO, A. S. Indicadores básicos de desempenho da justiça estadual de primeiro grau no Brasil. Texto para discussão, n. 1609. Brasília: Ipea, 2011.

CASTRO, M. F. A administração da justiça e os reflexos na economia. Revista CEJ, v. 6 n. 17, p. 10-18, 2002.

Comission Européenne Pour l'efficacité de la Justice (CEPEJ). Checklist pour la promotion de la qualité de la justice et des tribunaux. In: RÉUNION PLÉNIÈRE. 11. Procédures... Strasbourg: Cepej, p. 1-32, 2008.

CONSElho NaCiOnal De Justiça (CNJ). Resolução no 7, de 18 de outubro de 2005. Disciplina o exercício de cargos, empregos e funções por parentes, cônjuges e companheiros de magistrados e de servidores investidos em cargos de direção e assessoramento, no âmbito dos órgãos do Poder Judiciário e dá outras providências. Brasília: CNJ, 2005.

Resolução no 15, de 20 de abril de 2006. Dispõe sobre a regulamentação do Sistema de Estatística do Poder Judiciário, fixa prazos e dá outras providências. Brasília: CNJ, 2006.

Resolução no 76, de 12 de maio de 2009. Dispõe sobre os princípios do Sistema de Estatística do Poder Judiciário, estabelece seus indicadores, fixa prazos, determina penalidades e dá outras providências. Brasília: CNJ, 2009a.

Resolução $n$ o 88, de 8 de setembro de 2009. Dispõe sobre a jornada de trabalho no âmbito do Poder Judiciário, o preenchimento de cargos em comissão e o limite de servidores requisitados. Brasília: CNJ, 2009b.

Relatório final: metas de nivelamento do Poder Judiciário nacional 2009. Brasília: CNJ, 2010.

Relatório final: metas prioritárias do Poder Judiciário nacional 2010. Brasília: CNJ, 2011.

Relatório final: metas prioritárias do Poder Judiciário nacional 2011. Brasília: CNJ, 2012.

Metas nacionais do Poder Judiciário 2009-2012. Brasília: CNJ, 2013a.

Meta 18 - Combate à corrupção. Brasília: CNJ, 2013b. Disponível em: <http://www.cnj.jus.br/gestao-e-planejamento/metas/metas-2013/meta-18>. Acesso em: 30 de julho de 2013b.

CUNHA, L. Indicadores de desempenho do Judiciário: como são produzidos e qual a sua finalidade. Cadernos FGV Projetos, v. 5, n. 12, p.41-45, 2010. 
Departamento de Pesquisas JudiciáriAs (DPJ). Avaliação do desempenho judicial: desafios, experiências internacionais e perspectivas. Série CNJ Acadêmico, n. 5. Brasília: CNJ, 2011a.

100 maiores litigantes. Brasília: CNJ, 2011b.

100 maiores litigantes - 2012. Brasília: CNJ, 2012a.

Justiça em Números 2012. Brasília: CNJ, 2012b.

Justiça em Números 2013. Brasília: CNJ, 2013.

Justiça em Números 2014: ano base 2013. Brasília: CNJ, 2014.

Justiça em Números 2015: ano base 2014. Brasília: CNJ, 2015.

Justiça em Números 2016: ano base 2015. Brasília: CNJ, 2016.

DuBOIS, P. L.; BoYUM, K. O. Court reform: the politics of institutional change. In: HAYS, S.; GRAHAM JR., C. B. (Orgs.). Handbook of court administration and management. New York: Marcel Dekker, 1993. p. 27-52.

FAERMAN, S. R.; DIPADOVA, L. N.; QUINN, R. E. Judicial leadership in court management. In: HaYS, S.; GrahAM JR., C. B. (Orgs.). Handbook of court administration and management. New York: Marcel Dekker, 1993. p. 183-204.

FAIRBrother, P. Politics and the State as employer. Londres: Mansell, 1994.

FALCÃO, J. O Judiciário segundo os brasileiros. In: GUERRA, S. (Org.). Transformações do Estado e do direito: novos rumos para o Poder Judiciário. v. I. Rio de Janeiro: Editora FGV, 2009. p. 13-30.

Falcão, J.; Cerdeira, P. C.; Arguelhes, D. W. I relatório Supremo em Números: o múltiplo Supremo. Rio de Janeiro: Escola de Direito do Rio de Janeiro da Fundação Getúlio Vargas, 2011.

FALCÃo, J. et al. Il relatório Supremo em Números: o Supremo e a Federação. Rio de Janeiro: Escola de Direito do Rio de Janeiro da Fundação Getúlio Vargas, 2013.

FALCÃo, J.; OLIVEIRA, L. F. O STF e a agenda pública nacional: de outro desconhecido a supremo protagonista? Lua Nova, v. 88, p. 429-469, 2013.

Falcão, J.; HaRtManN, I. A.; Chaves, V. P. III relatório Supremo em Números: o Supremo e o Tempo. Rio de Janeiro: Escola de Direito do Rio de Janeiro da Fundação Getúlio Vargas, 2014.

Falcão, J.; Moraes, A.; HaRtMAnN, I. A. IV relatório Supremo em Números: o Supremo e o Ministério Público. Rio de Janeiro: Escola de Direito do Rio de Janeiro da Fundação Getúlio Vargas, 2015.

FaverI, D.; Pereira, C.; Oliveira, L. G. L. Ministério Público resolutivo? Uma análise da eficiência em ações extrajudiciais dos Ministérios Públicos Estaduais do Brasil. In: Encontro Nacional da AnPad, 38., Rio de Janeiro. Anais... Rio de Janeiro: Anpad, 2014. p. 1-16.

FochezATto, A. Análise da eficiência relativa dos tribunais de justiça estadual brasileira utilizando o método DEA. In: REUNIón DE ESTUdos REGIONALES - AECR, 36., Badajoz. Anais... Badajoz: AECR, 2010. p. 1-21. 
Fragale Filho, R. S. Poder Judiciário: os riscos de uma agenda quantitativa. In: COUtINHo, J. N. M.; MoRAIS, J. L. B.; StRECK, L. L. (Orgs.). Estudos constitucionais. Rio de Janeiro: Renovar, 2007.

Reconfigurações profissionais da magistratura: um exercício (preliminar) a partir da jurisprudência do Conselho Nacional de Justiça. In: CUNHA, J. R. (Org.). Poder Judiciário. Novos olhares sobre gestão e jurisdição. Rio de Janeiro: FGV, 2010. p. 97-126.

O Conselho Nacional de Justiça e seus possíveis impactos institucionais. In: Encontro Anual dA Anpocs, 35., Caxambu. Anais... Caxambu: Anpocs, 2011. p. 1-23.

Fundação Getúlio VARGAS (FGV). A reforma do Poder Judiciário no Estado do Rio de Janeiro. Rio de Janeiro: Editora FGV, 2005.

GALLAS, G. Court Reform: has it been built on an adequate foundation? Judicature, v. 63, p. 29-3, 1979.

GANGEMI, P. P.; FERNANDES, J. Os resultados do projeto CNJ/FGV: aplicação do BSC no Judiciário brasileiro. Cadernos FGV Projetos, v. 5, n. 12, p. 63-71, 2010.

GLICK, H. R. Courts, politics, and justice. 2. ed. New York: McGraw-Hill, 1988.

GoMeS, A. O.; GuIMARÃES, T. A. Desempenho do Judiciário. Conceituação, estado da arte e agenda de pesquisa. Revista de Administração Pública, v. 47, n. 2, p. 379-401, 2013.

Gonçalves, J. E. L. (Org.). A construção do novo Tribunal de Justiça do Estado de São Paulo. v. I. São Paulo: Plêiade, 2007a.

Gonçalves, J. E. L. (Org.). A construção do novo Tribunal de Justiça do Estado de São Paulo. v. II. São Paulo: Plêiade, 2007b.

GRAHAM JR., C. B. Reshaping the courts: traditions, management theories and political realities. In: HAYS, S.; GRAHAM JR., C. B. (Orgs.). Handbook of court administration and management. New York: Marcel Dekker, 1993. p. 3-26.

KAPLAN, R. S.; NORTON, D. Mapas estratégicos: convertendo ativos intangíveis em resultados tangíveis. Rio de Janeiro: Campus, 2004.

Karasin, S.; Rodovalho, M. F. T. Contradições do Poder Judiciário brasileiro. GV Executivo, v. 11, n. 2, p. 82, 2012.

LEVITT, M.; JOYCE, M. The growth and efficiency of public spending. Cambridge: Cambridge University Press, 1988.

LEWIN, A. Y.; MOREY, R. C.; COOK, T. J. Evaluating the administrative efficiency of courts. Omega - International Journal of Management Science, v.10, p. 401-411, 1982.

MANZINI, R. O desdobramento da estratégia através do Balanced Scorecard: lições da experiência no Poder Judiciário nacional. Cadernos FGV Projetos, v. 5, n. 12, p. 53-62, 2010.

MARANHÃo, M. O alinhamento estratégico no Poder Judiciário, garantido pela Comissão de Gestão Estratégica e Assessoria de Desenvolvimento Institucional. In: FUndAÇÃo GetúlIo VARGAS (FGV). A reforma do Poder Judiciário no Estado do Rio de Janeiro. Rio de Janeiro: Editora FGV, 2005. p. 37-46. 
Maravall, J. M.; Przeworski, A. Introduction. In: Maravall, J. M.; PrzeWorski, A. (Eds). Democracy and the rule of law. Cambridge: Cambridge University Press, 2003. MeIRELES, A. M. R. Uma proposta de SAD para avaliação da eficiência do Poder Judiciário do Estado do Ceará utilizando AED. Fortaleza: Universidade Estadual do Ceará, 2012. Dissertação (Mestrado) - Universidade Estadual do Ceará; Instituto Federal de Educação, Ciência e Tecnologia do Ceará, Fortaleza.

Meneses, R. S.; OliveiRA, L. G. L.; VAsconcelos, T. J. M. O gerenciamento de projetos em um tribunal de justiça: análise dos prazos dos projetos estratégicos 20102014. Revista de Gestão e Projetos (GeP), v. 7, n.3, p. 93-107, set./dez. 2016.

Montesquieu, C. S. Do espírito das leis. São Paulo: Difusão Europeia do Livro, 1962. MoREY FILHO, F. B.; CrÉDICO, R. G. O papel da assessoria de planejamento e gestão no Tribunal de Justiça. In: GonçALVES, J. E. L. (Org.). A construção do novo Tribunal de Justiça do Estado de São Paulo. v. II. São Paulo: Plêiade, 2007. p. 143-154.

MotTA, P. R. M. Revendo estrategicamente as organizações do Poder Judiciário: uma perspectiva gerencial. Cadernos FGV Projetos, v. 5, n. 12, p. 24-31, 2010.

Nogueira, J. M. M. A gestão do Poder Judiciário: uma análise do sistema de mensuração de desempenho do Judiciário brasileiro. São Paulo: FGV, 2010. Dissertação (Mestrado) - Escola de Administração de Empresas de São Paulo, Fundação Getulio Vargas, São Paulo.

. A ausência do Poder Judiciário enquanto objeto de estudo da Administração Pública brasileira. Díke - Revista eletrônica da ESMEC, v. 1, n.1, p. 1-17, 2011.

NogueirA, J. M. M. et al. Estudo exploratório da eficiência dos tribunais de justiça estaduais brasileiros usando a análise envoltória de dados (DEA). Revista de Administração Pública, v. 46, n. 5, p. 1317-1340, 2012.

OLIVEIRA, L. G. L. Reflections on the role of the CNJ in relation to the Executive and Legislative. In: Annual ASSEmbly CladeA, 48., Rio de Janeiro. Anais... Rio de Janeiro: Ebape-Fgv, 2013. p. 1-7.

OliveirA, L. G. L.; Pontes, D. S.; SoARes, M. N. M. A atuação da Assessoria de Planejamento do TJCE na revisão e acompanhamento do plano estratégico do Judiciário cearense. Themis - Revista da ESMEC, v. 12, n.1, p. 355-373, 2014.

OliveirA, L. G. L.; NogueirA, J. M. M. A ausência do Poder Judiciário na Administração Pública brasileira: uma análise de 2009 a 2014. FFBusiness, v. 15, n. 21, p. 1-15, 2017.

OLIVEIRA, L. G. L. et al. Medição da eficiência de magistrados e de unidades judiciárias no Ceará. Cadernos Ebape.br, v. 14, n. 3, p. 836-857, 2016.

ORdEM dos AdVogados do BRASIL (OAB). Pesquisa: o que pensa o brasileiro sobre a Justiça. 10 de novembro, 2003.

PINHeIRo, A. C. Direito e economia num mundo globalizado: cooperação ou confronto? Texto para discussão, n. 963. Rio de Janeiro, Ipea, 2003.

POLLIT, C. Managerialism and the public service. Oxford: Blackell, 1990.

Pontes, D. S.; Oliveira, L. G. L.; Vasconcelos, T. J. M. Os condicionantes de desempenho dos projetos estratégicos em um tribunal de justiça. Revista de Gestão e Projetos (GeP), v. 6, n.1, p. 14-27, jan./abr. 2015 
Rodovalho, M. F. T. Reforma do Estado após a emenda constitucional 45/04: a reforma do Poder Judiciário. São Paulo: FGV, 2012. Tese (Doutorado) - Escola de Administração de Empresas de São Paulo, Fundação Getulio Vargas, São Paulo.

Atlas, 2014.

. A Reforma do Poder Judiciário: análise do papel do STF e do CNJ. São Paulo:

SADEK, M. T. O Poder Judiciário na reforma do Estado. In: BRESSER-PEREIRA, L. C.; WILHEIM, J.; SolA, L. (Orgs.). Sociedade e Estado em transformação. São Paulo: Editora Unesp, 1999.

. Judiciário: mudanças e reformas. Estudos Avançados, v. 18, n. 51, p. 19101, 2004.

Magistrados: uma imagem em movimento. Rio de Janeiro: Editora FGV, 2006.

SAdek, M. T.; OliveirA, F. L. Estudos, pesquisas e dados em Justiça. In: Oliveira, F. L. (Org.) Justiça em foco: estudos empíricos. Rio de Janeiro: Editora FGV, 2012. p. 15-61.

SANTOS, A. M.; DA Ros, L. Caminhos que levam à corte: carreiras e padrões de recrutamento dos ministros dos órgãos de cúpula do Poder Judiciário brasileiro (1829-2006). Revista Sociologia e Política. v. 16, n. 30, p. 131-149, 2008.

SAUERBronN; J. F. R.; LODI, M. D. F. Construção da imagem institucional do Poder Judiciário - uma análise baseada nas campanhas publicitárias do Conselho Nacional de Justiça. Cadernos EBAPE.BR, v. 10, n.4, p. 925-945, 2012.

SAuerbronn, F. F.; SAUerbronn, J. F. R. Representações sociais da Reforma do Judiciário - estudo baseado nas perspectivas dos servidores do Tribunal de Justiça do Estado da Bahia. Revista de Administração Pública, v. 40, n. 3, p. 719-737, 2015.

SAUERBronn, F. F. et al. Estratégia e gestão do Poder Judiciário: uma proposta de estudo das práticas sociais relacionadas ao BSC. Revista do Serviço Público, v. 67, n.1, p. 8-31, 2016.

SAUERBRonN, F. F.; LouREnço, R. L. Evolução recente na Reforma do Judiciário e representações sociais nas perspectivas de magistrados do Tribunal de Justiça do Estado da Bahia. In: Encontro NACIONAL DA ANPAD, 40., Costa do Sauipe. Anais... Costa do Sauipe: Anpad, 2016. p. 1-15.

Sherwood, R. B.; Shepherd, G.; SouzA, C. M. Judicial systems and economic performance. The Quartely Review of Economics and Finance, v. 34, p. 101-116, 1994.

SIlva, J. A.; Florêncio, P. A. E. L. Políticas judiciárias no Brasil: o Judiciário como autor de políticas públicas. Revista do Serviço Público, v. 62, n. 2, p.119-136, 2011.

SILVESTRE, A. R. M. Gerenciamento de projetos: uma análise das lições aprendidas dos projetos de um Tribunal de Justiça. Fortaleza: Universidade Estadual do Ceará, 2016. Monografia (Graduação) - Centro de Estudos Sociais Aplicados, Universidade Estadual do Ceará, Fortaleza.

Supremo Tribunal Federal (STF). Súmula Vinculante no 13. Diário da Justiça. 29 de agosto de 2008, 1. Brasilia: STF, 2008. 
TAYLOR, M. M. O Judiciário e as políticas públicas no Brasil. Dados. v. 50, n. 2, p. 229257, 2007.

TAYLOR, M. M. Judging policy: courts and policy reform in democratic Brazil. Stanford, CA: Stanford University Press, 2008.

TAYLOR, M. M.; DA ROS, L. Os partidos dentro e fora do poder: a judicialização como resultado contingente da estratégia política. Dados, v. 51, n. 4, p. 825-864, 2008.

Tocqueville, A. Democracy in America. Hertfordshire: Wordsworth Editions, 1998.

VIEIRA, L. J. M.; PINHEIRo, I. A contribuição do Conselho Nacional de Justiça para a gestão do Poder Judiciário. In: ENCONTRO NACIONAL DA ANPAD, 32., Rio de Janeiro. Anais... Rio de Janeiro: Anpad, 2008. p. 1-16.

VIEIRA, L. J. M.; COSTA, S. G. Liderança no Judiciário: o reconhecimento de magistrados como líderes. Revista de Administração Pública, v. 47, n. 4, p. 927-948, 2013.

YEUNG, L. L. Além dos "achismos", do senso comum e das evidências anedóticas: uma análise econômica do Judiciário brasileiro. São Paulo: FGV, 2010. Tese (Doutorado) Escola de Economia de São Paulo, Fundação Getulio Vargas, São Paulo.

YEUNG, L. L.; AzEVEDO, P. F. Measuring efficiency of Brazilian courts with data envelopment analysis (DEA). IMA Journal of Management Mathematics, v. 22, p. 343-356, 2011.

Leonel Gois Lima Oliveira

Possui doutorado em Administração pela Escola Brasíleira de Administração Pública e de Empresas da Fundação Getúlio Vargas (Ebape-FGV). Atualmente é Técnico Judiciário, exercendo o cargo de Auditor Chefe do Tribunal de Justiça do Estado do Ceará (TJCE), e professor da Escola Superior de Magistratura do Estado do Ceará (Esmec). Contato: leonelgois@tjce.jus.br / leonel.oliveira@fgv.br 